\title{
Female ornamentation influences male courtship investment in a lizard
}

\section{Devi Stuart-Fox * and Jennifer L. Goode}

Zoology Department, The University of Melbourne, Parkville, VIC, Australia

\section{Edited by:}

Wayne I. L. Davies, The University of Western Australia, Australia

Reviewed by:

Jan M. Hemmi, The University of Western Australia, Australia

Jennifer Kelley, The University of Western Australia, Australia

Cristiano Bertolucci, University of Ferrara, Italy

Devi Stuart-Fox, Zoology

Department, The University of Melbourne, Building 147, Royal

Parade, Parkville, VIC 3010, Australia e-mail:devis@unimelb.edu.au

\section{*Correspondence:}

Female signals of reproductive status often comprise both distinctive color patches and behaviors but their relative influence on male courtship investment is unclear. We examined the role of female-specific coloration in signaling reproductive condition and quality to males in the Lake Eyre dragon lizard, Ctenophorus maculosus. Females of this species develop intense orange ventral coloration when sexually receptive, which fades to white only after laying. To separate the effect of color and behavior, we manipulated the presence of female orange ventral coloration within different periods of the reproductive cycle in which females display qualitatively different behaviors. In a separate manipulation, we tested whether the presence of an ultraviolet (UV) component, size and intensity of female orange patches influenced male courtship investment. Males tended to chase, bite, and copulate more with orange than white females, irrespective of reproductive state. However, males copulated much more frequently with receptive females than non-receptive or gravid females, consistent with females' behavioral acceptance of copulations during this stage. Males courted females with small orange patches the most, and had an overall preference for intense color patches (as opposed to pale orange patches), regardless of the presence of UV. Our results suggest that female orange coloration signals reproductive condition, specifically receptivity, and that small, intensely orange patches signal that females are more likely to be receptive. Female ornamentation therefore encodes information used by males to make decisions regarding courtship investment.

Keywords: female-specific coloration, color, signaling, female resistance, male courtship, harassment, sexual conflict

\section{INTRODUCTION}

The function and evolution of female ornamentation in species with conventional sex roles has received increasing attention over recent years. This interest is largely due to the historical bias toward male ornaments, with female ornamentation generally viewed as a less showy version of the male ornament, and attributed to genetic correlation between the sexes (Amundsen, 2000a,b; Kraaijeveld et al., 2004; Rubenstein, 2012; Tobias et al., 2012). Current evidence for direct selection on female ornamentation is mixed, with the great majority of studies focussing on mutually ornamented species, especially birds (reviewed in Nordeide et al., 2013). However, some of the strongest evidence for direct selection on female ornamentation derives from species in which only females possess the ornaments (e.g., Watson and Simmons, 2010). Species with female-specific ornamentation are particularly good models for studying the function and evolution of female ornamentation because genetic correlation between the sexes can be ruled out.

Direct selection on female ornamentation in species with conventional sex roles can occur as a result of female-female competition, male mate choice or sexual conflict. Females may compete directly for mates, with female ornamentation functioning as a signal in female-female competition (Rubenstein and Lovette, 2009; Baldauf et al., 2011). Females may also compete for resources such as food or space, even when they do not compete directly for access to mates (Watson and Simmons, 2010). Alternatively (or additionally), female ornamentation may signal aspects of female quality and be used by males to make decisions about courtship investment and mate choice (Rowland, 1982; LeBas and Marshall, 2000; Amundsen and Forsgren, 2001; Gladbach et al., 2010; Baldauf et al., 2011). Males may need to make strategic decisions regarding courtship investment when courtship is costly (e.g., energy intensive, prolonged, increases predation risk). Finally, female ornamentation can evolve under sexual conflict to mimic male coloration as a means to reduce male harassment, or to signal receptivity or signal lack of receptivity to minimize courtship and harassment outside the receptive period (Gosden and Svensson, 2009; Xu and Fincke, 2011).

Female-specific coloration is a common form of female ornamentation and is often exhibited during specific periods of the reproductive cycle. Such female coloration may signal a combination of reproductive maturity, physiological receptivity or lack or receptivity, as well as aspects of reproductive quality, and be used by males to make decisions regarding courtship investment (Cooper and Greenberg, 1992; Baird, 2004; Baldauf et al., 2011; Olsson et al., 2013). Males are expected to invest more toward courting females that are reproductively mature, physiologically receptive and of higher quality in terms of size, condition, or other indicators of potential reproductive output. Female reproductive quality may be signaled by various components of female coloration such as intensity, size, and presence of ultraviolet 
(UV) (LeBas and Marshall, 2000; Amundsen and Forsgren, 2001; Gladbach et al., 2010). For example, male ornate dragon lizards, Ctenophorus ornatus, appear to prefer females with higher throat UV reflectance (LeBas and Marshall, 2000). Although a number of studies have manipulated male coloration to assess its role in female mate choice (e.g., Andersson and Amundsen, 1997; Kemp, 2008; Lim et al., 2008; Bajer et al., 2010), few studies have accurately manipulated aspects of female coloration, including the presence of UV.

We tested whether males vary their courtship investment in relation to female coloration in the Lake Eyre dragon, Ctenophorus maculosus, an ecologically specialized lizard found exclusively on large arid salt pans of Australia's southern interior (Mitchell, 1973; Olsson, 1995b). We focused on male courtship investment toward females because the species has conventional sex roles, a promiscuous mating system, neither sex provides parental care, males provide no direct resources to females and oviposition sites are not limited (Mitchell, 1973; Olsson, 1995b). Therefore, female-female competition for mates or resources is unlikely to be principally driving the evolution of female ornamentation in this species. During the breeding season, mature females develop intense orange ventro-lateral color patches, whereas male ventral coloration remains white or lightly speckled with rusty orange. Females develop orange coloration prior to becoming sexually receptive and maintain it until they lay, after which it rapidly fades to white or very pale orange speckles (Chan et al., 2009). The orange patches intensify again if females become sexually receptive a second time during the breeding season (Chan et al., 2009).

Males persistently court and harass females, and often attempt forced copulation, which can result in injury or death from the male's mating grasp (Mitchell, 1973; Olsson, 1995a,b). Males court and harass orange females more than white females (Chan et al., 2009). Furthermore, males court and harass orange females irrespective of their reproductive condition, including gravid females, presumably due to female sperm storage (Mitchell, 1973). In response, gravid females perform rejection behaviors including lateral displays and flipping onto their backs, a position which prevents copulation. Because these rejection behaviors emphasize the orange ventro-lateral coloration, the species has been cited as an example of female ornamentation having evolved under sexual conflict (e.g., in Birkhead, 1995; Gavrilets et al., 2001; Eberhard, 2002; Cunningham, 2003; Shine et al., 2003; Shine and Mason, 2005). However, the relative roles of color and behavior in signaling lack of receptivity are unclear and the relationship between female coloration, reproductive quality and male courtship investment are not known. We therefore manipulated female coloration independently of reproductive status/behavior to clarify the roles of color and behavior in signaling reproductive condition to males. We also tested whether males altered their courtship investment based on differences in specific aspects of female coloration: patch size, intensity, or presence/absence of an UV component. Importantly, we matched paints used for color manipulations to natural lizard colors and modeled conspicuousness of those colors to the lizard visual system. Given the climatically extreme habitat and limited food resources [the species subsists on one species of ant and dead insects that blow onto the salt crust (Mitchell, 1973)]; we expected males to make strategic decisions regarding courtship investment.

\section{METHODS STUDY SYSTEM}

We used a total of 24 females and 22 males hand caught from Lake Eyre (Chan et al., 2009; McLean et al., 2010), and housed at the University of Melbourne Animal House Facility in individual $61 \times 30 \times 30 \mathrm{~cm}$ glass tanks, separated by opaque dividers. We used an additional 10 captive bred females and 5 males that hatched between October 2007 and February 2008. We tested for a difference in the behavior of wild-caught and captive bred lizards in all initial statistical tests but as none were detected, both were used. All animals were reproductively mature adults [mean female snout-vent length $(\mathrm{SVL})=61.2$; range $=56-65 \mathrm{~mm}$; $\mathrm{min}$ imum female size at sexual maturity $=48 \mathrm{~mm}$; mean male $\mathrm{SVL}=$ 67.5 ; range $=61-73 \mathrm{~mm}$; minimum male size at sexual maturity $=54 \mathrm{~mm}]$. Each tank contained a layer of sand and salt crust to mimic natural habitat and was fitted with a heat and UV lamp. The room was maintained at an average temperature of $28^{\circ} \mathrm{C}$ on a 12:12 day: night cycle. The tanks were watered to keep the sand moist and lizards were fed crickets (Anchieta domesticus) dusted with calcium and vitamins three times a week. We conducted behavioral trials over the lizards' breeding season from September 2009 until February 2010 and ran experiments between 0900 and $1300 \mathrm{~h}$.

The female reproductive cycle can be broadly categorized into three stages during which females display different behaviors to approaching males: (1) non-receptive-prior to becoming receptive females are naturally white and exhibit a high frequency of "appeasement" behaviors such a arm-waving (slow, circular movement of one of the front arms) and head-bobbing; (2) receptive-females develop ventro-lateral orange coloration and accept male courtship and copulations and (3) gravid-females are not sexually receptive, retain ventro-lateral orange coloration and display courtship rejection behaviors to approaching males (Chan et al., 2009). Female courtship rejection behaviors include lateral displays, where females laterally compress their body, extend their throats and perform hind-leg push-ups (similar to male aggressive displays) and emphasize their ventro-lateral orange patches. This behavior is also sometimes accompanied by a stiffened walk. If a male persists in courting or harassing a female, the female flips onto her back to avoid forced copulation. Male courtship behavior includes head-bobs, push-ups, and leaps toward the female while harassment behavior includes chases and bites (attempts at gaining a mating grasp on the female's neck). Males also display aggressive behavior comprising a lateral display, usually in response to female lateral displays.

\section{MATCHING PAINTS TO NATURAL LIZARD COLORS}

We matched paints to natural female coloration by comparing the spectral reflectance of natural lizard colors with that of each paint treatment (white, black, gray, orange, no-UV, and pale; see experimental design below and Figure 1). For reflectance measurements, we used an Ocean Optics USB2001 spectrometer connected to a laptop computer running Ocean Optics SpectraSuite Software and a Pulsed Xenon lamp (PX-2). 


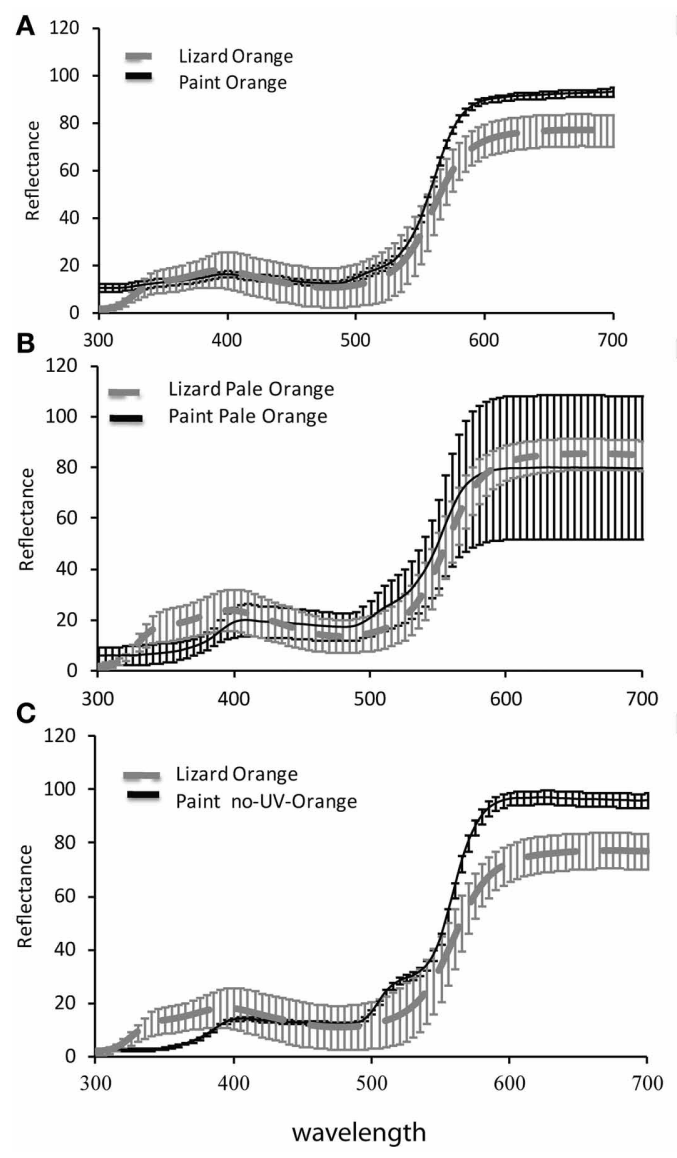

FIGURE 1 | Reflectance spectra of paints for (A) orange (B) pale orange (C) no-UV-orange (D) white (E) gray and (F) black, applied to Ctenophorus maculosus females compared with reflectance spectra of natural female coloration. Data of paints are
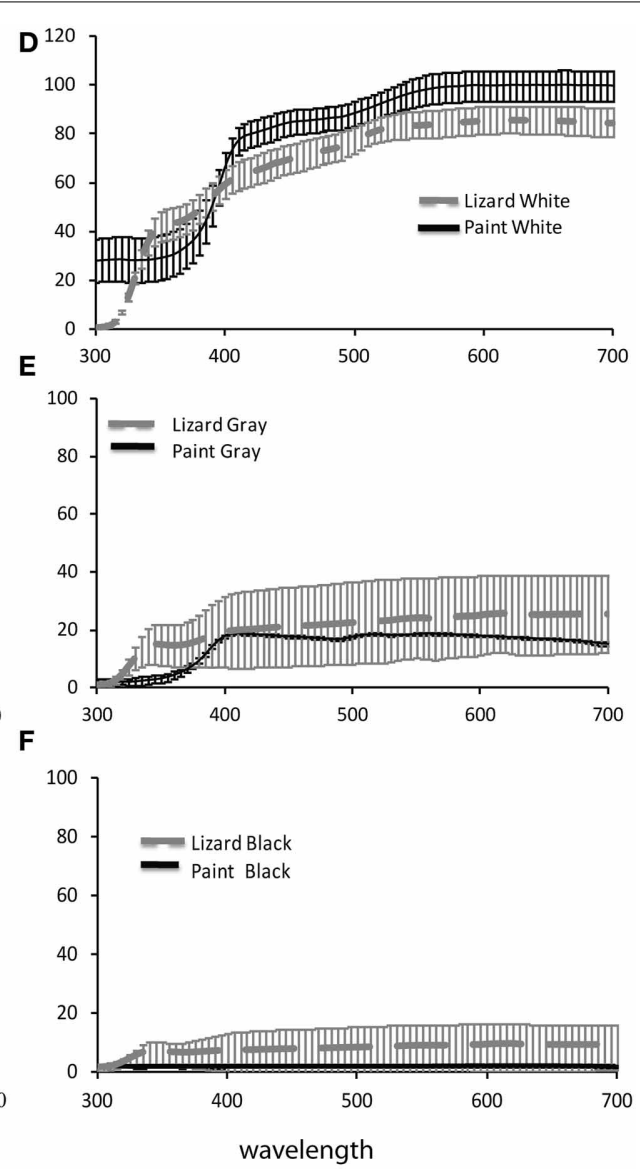

mean \pm standard deviation reflectance measurements of paints applied to 3 lizards respectively and natural female coloration are mean \pm standard deviation of reflectance measurements from 18, 18, 10, 10, 7 , and 8 lizards respectively.
Reflectance readings were taken at a $30^{\circ}$ angle to the surface and calibrated using a Spectralon white certified reflectance standard (USRS-99-010; Labsphere Inc, North Sutton, NH). As natural female coloration (both white and orange) reflect light in the UV, whereas acrylic paints do not, we sourced paints containing a UV reflecting component (Reel Wings Decoys Co Inc.). We designed paints to match natural white and orange ventral lizard coloration and natural black or gray gular stripe coloration in both chromatic (color) and achromatic (luminance) contrast against the salt crust background as closely as possible (Figure 1). For spectral reflectance measurements we applied each differing color treatment (orange, pale and no UV) to the ventral region of three non-receptive (naturally white) females (Figures 2, 3).

To check how closely our paints matched natural female lizard coloration from a lizard's point of view, we compared the chromatic (color) and achromatic (luminance) contrast of lizard colors against the natural salt crust background of Lake Eyre with those of paint colors against the same background. To calculate chromatic and achromatic contrasts, we applied the model of Vorobyev and Osorio (1998), which estimates the discriminability (contrast) of two colors in units of just noticeable differences (JNDs). For analysis, all spectral data (paints, lizards, and backgrounds) were averaged over each 5-nm inter$\mathrm{val}$, in the rage $300-700 \mathrm{~nm}$ (Figure 1), the approximate visual spectrum of diurnal lizards (Loew et al., 2002). We applied model calculations as detailed in (Stuart-Fox et al., 2003; Siddiqi et al., 2004; Chan et al., 2009). Application of this model requires data on irradiance (i.e., illumination), the spectral sensitivities of the receiver's photoreceptors (in this case lizards) and the reflectance of lizard and background colors. Lizard spectral sensitivities, irradiance and background spectra are the same as those in Chan et al. (2009). We used an irradiance spectrum representing full sunlight, reflectance measures of salt crust of Lake Eyre (Chan et al., 2009; McLean et al., 2010), which is the natural habitat of this species, and data on the spectral sensitivities of a closely related lizard, Ctenophorus ornatus (Barbour et al., 2002). Although our models are not based on spectral sensitivities of Ctenophorus maculosus, the visual systems of diurnal lizards are conserved to the extent that our results are likely to be robust to minor variations among species (Olsson et al., 2013). 


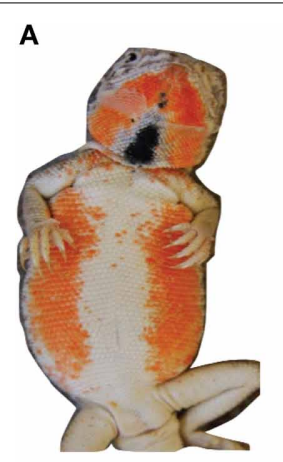

C

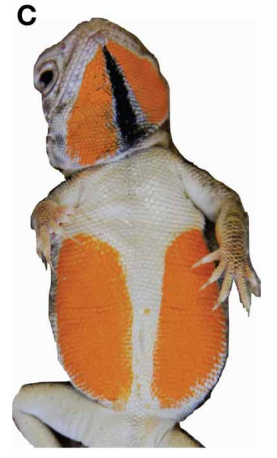

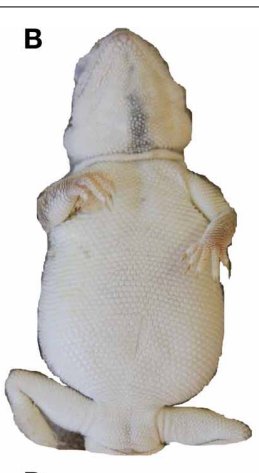

D

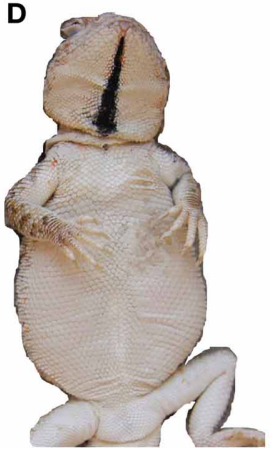

FIGURE 2 | Natural Ctenophorus maculosus female coloration and manipulated paint treatments. (A) naturally orange female (B) naturally white female (C) orange painted female (D) white painted female.

\section{EXPERIMENT 1}

To tease apart the role of color from behavior in signaling female reproductive status to males, we manipulated female coloration within each of the three stages of the reproductive cycle (nonreceptive, receptive and gravid), which correspond to clear behavioral differences (Chan et al., 2009). We used a repeated measures design with each female in six treatments: painted either white or orange (with black throat stripe, see below) in each of the three reproductive stages (Figure 2). The order of paint manipulation within each stage (white or orange) was random.

Twenty-five females were used in experiments for the nonreceptive stage, and of those, 19 developed orange coloration and showed behavioral signs of receptivity so were also used in experiments for receptive and gravid stages. Due to missing data for some treatments, 25 females were used in 47 trials for the nonreceptive stage, 16 females were used in 27 trials for the receptive stage and 19 females were used in 34 trials for the gravid stage (total $=108$ trials). Twenty-three males were used in an average of $4.7 \pm 0.48 S E$ trials each based on pilot experiments testing males for consistent courtship of females.

After applying the color treatment to a given female we placed her back in her home tank and allowed a few minutes for her to reacclimate. Once the female was calm we placed a male in her tank and the behavioral interaction was recorded using a Panasonic SDR- H250 digital video camera for approximately $15 \mathrm{~min}$, after which the males was removed from the female's tank. Males were assigned to females so that no female was paired with the same male more than once. No female was used in more than one behavioral trial within 2 consecutive days.

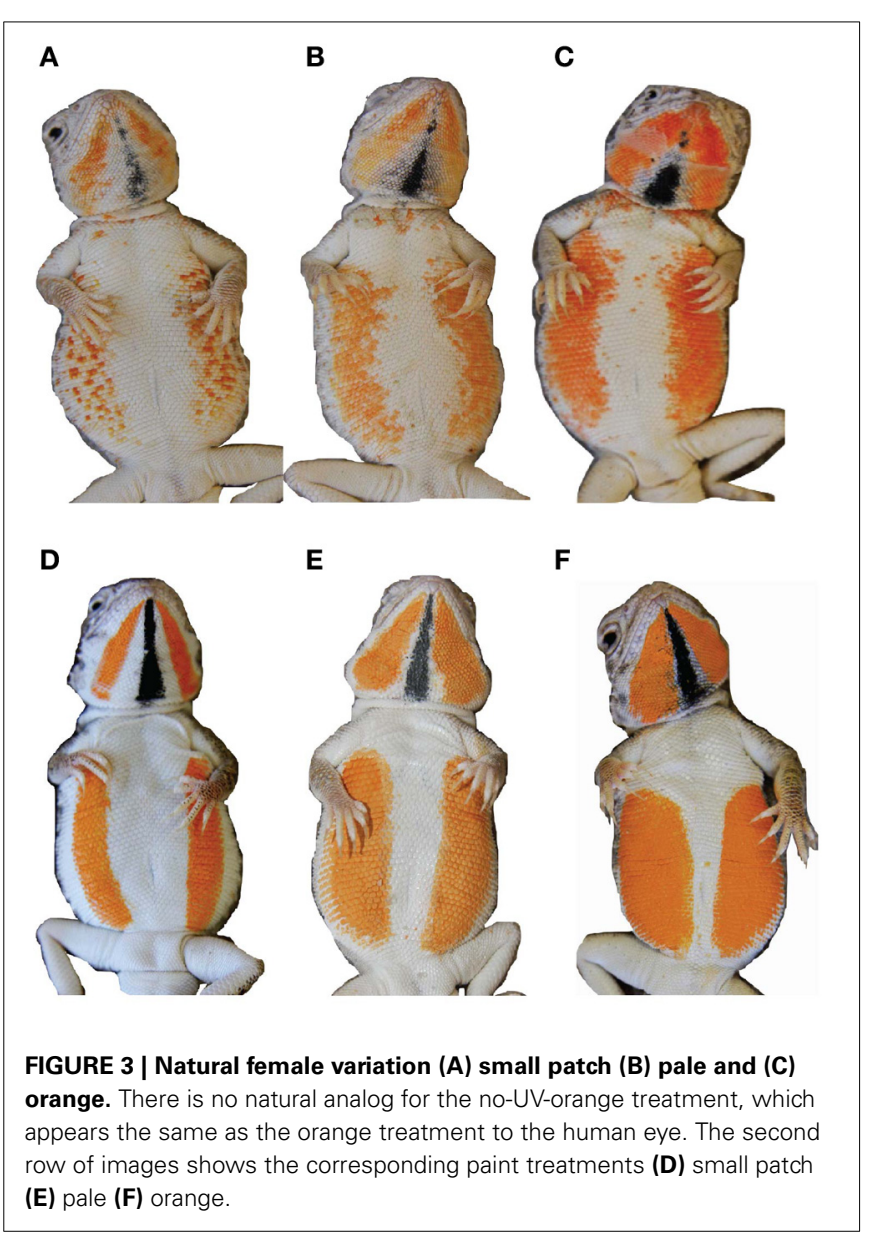

\section{EXPERIMENT 2}

To test whether males varied their courtship based on female coloration we painted non-receptive (naturally white) females with four different paint treatments relating to the variation seen in natural female coloration, except for the treatment with no UV for which there is no natural analog (Figure 3). This allowed us to assess male courtship investment and persistence toward females that differed in color but were in the same reproductive condition (and therefore behaved similarly). The treatments were large orange patches, small orange patches, pale orange patches, and orange patches with no UV (Figure 3). As females develop a thin black stripe in the center of their throats concurrently with the orange ventro-lateral patches, we painted a black throat stripe on females with large, small and no-UV patches and a gray throat stripe on females with pale patches. As the period we were able to conduct trials was restricted to when females were nonreceptive, we were unable to apply all four paint treatments to each female. We conducted a total of 70 trials on 31 females, and no female was used more than once within two consecutive days. Where females received more than one treatment, the treatments were applied in random order. We used 22 different males an average of $3 \pm 0.34 S E$ times each and males were assigned to females so that no female was paired with the same male more than once. 


\section{BEHAVIOR SCORING}

We scored male and female behaviors from video footage using Jwatcher (Blumstein and Daniel, 2007). We recorded the frequency or duration of each behavior per minute of active trial time (logtransformed) where "active trial time" was the time from the first behavior until the end of the $15 \mathrm{~min}$ trial minus the time that either individual spent out of view (e.g., under salt crust). We recorded latency duration as the time until the first male or female behavior. For females, we recorded the number of arm waves, the number of times they ran away and the duration of lateral displays and flips. For males we recorded the number of head bobs, push ups, lateral displays, chases, and bites. We also recorded the number and duration of copulations.

\section{DATA ANALYSIS}

Male and female behavior for experiment 1 were analyzed using repeated measures generalized linear mixed models (GLMM) with each behavior as the response variable and color (orange or white) and reproductive stage (non-receptive, receptive and gravid) and their interaction as fixed effects (PROC MIXED, SAS 9.1). To account for repeated use of females, we included female ID as the blocking factor with the combination of color and reproductive stage (i.e., color*stage) as the repeated measure within each block (i.e., female). To account for repeated use of males and a potential trial order effect, we also included male ID and trial date as random factors. Male behavior for experiment 2 was analyzed using GLMMs with color treatment (large orange patch, small orange patch, orange-no-UV, and pale orange patch) as the fixed effect and female ID, male ID and order as random variables. We assessed significance levels of GLMMs using False Discovery Rate (FDR) to account for multiple tests; i.e., one for each behavior (Verhoeven et al., 2005). For significant results, we used Tukey-Kramer tests for post-hoc comparisons (reported $p$-values adjusted for multiple comparisons).

\section{RESULTS}

\section{MATCH OF PAINTS TO LIZARD COLORS}

Despite the close match of reflectance spectra of paints and natural lizard colors (Figure 1), all paints had slightly higher achromatic and chromatic contrast (against a natural background to the lizard visual system) than their natural corresponding colors viewed against the same background (One-way ANOVAs: $P<0.02$ in all cases), except for black and gray which had a chromatic contrast that matched lizard coloration and gray which had a lower achromatic contrast than natural lizard coloration $\left[F_{(2)}=\right.$ $21.98, P=0.0003]$. Visual models suggested that the differences between paint treatments are clearly perceptible to the visual system of lizards. Specifically, orange paint treatments (orange, pale orange, and no-UV-orange) differed in both chromatic $\left[F_{(2)}=\right.$ 64.53; $P<0.0001]$ and achromatic contrasts $\left[F_{(2)}=20.84 ; P<\right.$ 0.0001]. Post-hoc Tukey tests revealed significant differences in all pairwise comparisons except the achromatic contrast of pale and no-UV-orange $(P<0.01$ in all cases; Table 1$)$. No-UV-orange had significantly higher chromatic contrast than either orange or pale orange paints, with the latter having the lowest chromatic contrast to the salt crust background. In terms of achromatic contrast, pale and no-UV-orange did not differ from each other
Table 1 | Chromatic and achromatic (luminance) contrasts against the natural salt crust background for each paint treatment.

\begin{tabular}{lcc}
\hline Paint treatment & Chromatic contrast & Achromatic contrast \\
\hline Orange & $15.99 \pm 1.49$ & $17.43 \pm 0.44$ \\
No-UV-orange & $22.68 \pm 2.5$ & $19.18 \pm 0.63$ \\
Pale & $13.79 \pm 1.12$ & $19.52 \pm 1.02$ \\
\hline
\end{tabular}

Values are JNDs of paints measured on three different females \pm the standard deviation.

Table 2 | The effects of color, female reproductive stage and their interaction on the behaviors of female lizards.

\begin{tabular}{|c|c|c|c|c|}
\hline Behavior class & Behavior & Fixed effects & $F_{d f}$ & $\boldsymbol{P}$ \\
\hline \multirow[t]{9}{*}{ Appeasement } & Latency (D) & Color & $0.022_{1,71}$ & 0.875 \\
\hline & & Stage & $13.97_{2,71}$ & $<0.0001 * * *$ \\
\hline & & Color*stage & $0.022,71$ & 0.984 \\
\hline & Armwaves & Color & $0.041,71$ & 0.836 \\
\hline & & Stage & $14.48_{2,71}$ & $<0.0001 * * *$ \\
\hline & & Color*stage & $0.172,71$ & 0.841 \\
\hline & Run away & Color & $2.57_{1,70}$ & 0.114 \\
\hline & & Stage & $17.86_{2,70}$ & $<0.0001 * * *$ \\
\hline & & Color*stage & $0.15_{2,70}$ & 0.859 \\
\hline \multirow[t]{6}{*}{ Rejection } & Flip (D) & Color & $1.12_{1,71}$ & 0.725 \\
\hline & & Stage & $20.58_{2,71}$ & $<0.0001 * * *$ \\
\hline & & Color*stage & $0.04_{2,71}$ & 0.957 \\
\hline & Lateral Display (D) & Color & $0.35_{1,70}$ & 0.558 \\
\hline & & Stage & $33.562,70$ & $<0.0001 * * *$ \\
\hline & & Color*stage & $0.03_{2,70}$ & 0.9712 \\
\hline
\end{tabular}

(D), duration. Boldface indicates statistical significance and asterisk indicates significance after False Discovery Rate correction.

but both had a significantly higher achromatic contrast than orange.

\section{EXPERIMENT 1: DISTINGUISHING THE ROLE OF COLOR FROM BEHAVIOR}

As expected, female behavior differed greatly depending on reproductive condition (Table 2). Females performed arm waves and head bobs ("appeasement" behaviors) significantly more often during the non-receptive stage (irrespective of color) than during both receptive and gravid stages [arm waves: non-receptive vs. receptive: $t_{(71)}=4.60, P<0.0001$; non-receptive vs. gravid: $t_{(71)}=4.37, P<0.0001$; head bobs: non-receptive vs. receptive: $t_{(70)}=4.60, P \geq 0.0001$ and non-receptive vs. gravid: $t_{(70)}=$ 4.22, $P<0.0001$ respectively]. Females also performed more courtship rejection displays comprising lateral displays and flips while they were gravid than when they were non-receptive or receptive [lateral displays: $t_{(70)}=7.62, P<0.0001$; flips: $t_{(71)}=$ 4.16, $P<0.0001]$.

Males courted all females with push-ups and head bobs regardless of their color, reproductive stage or their interaction (Table 3). However, there was a trend for males to 
Table 3 | The effects of color, female reproductive stage and their interaction on the behaviors of male lizards.

\begin{tabular}{|c|c|c|c|c|}
\hline Behavior class & Behavior & Fixed effects & $F_{d f}$ & $P$ \\
\hline & Latency (D) & Color & $2.45_{1,71}$ & 0.122 \\
\hline & & Stage & $0.72_{2,71}$ & 0.49 \\
\hline & & Color*stage & $0.29_{2,71}$ & 0.748 \\
\hline \multirow[t]{6}{*}{ Courtship } & Head bobs & Color & $0.05_{1,71}$ & 0.828 \\
\hline & & Stage & $2.19_{2,71}$ & 0.119 \\
\hline & & Color*stage & $0.01_{2,71}$ & 0.99 \\
\hline & Push ups & Color & $0.01_{1,71}$ & 0.750 \\
\hline & & Stage & $1.57_{2,71}$ & 0.215 \\
\hline & & Color*stage & $0.01_{2,71}$ & 0.992 \\
\hline \multirow[t]{3}{*}{ Aggression } & Lateral display & Color & $0.11_{1,71}$ & 0.736 \\
\hline & & Stage & $4.81_{2,71}$ & $0.011^{*}$ \\
\hline & & Color*stage & $0.05_{2,71}$ & 0.949 \\
\hline \multirow[t]{6}{*}{ Harassment } & Chases & Color & $4.73_{1,70}$ & 0.033 \\
\hline & & Stage & $1.58_{2,70}$ & 0.214 \\
\hline & & Color*stage & $0.55_{2,70}$ & 0.581 \\
\hline & Bites & Color & $4.82_{1,70}$ & 0.032 \\
\hline & & Stage & $0.74_{2,70}$ & 0.48 \\
\hline & & Color*stage & $0.64_{2,70}$ & 0.529 \\
\hline \multirow[t]{6}{*}{ Copulation } & Copulation & Color & $4.13_{1,71}$ & 0.046 \\
\hline & & Stage & $12.7_{2,71}$ & $<0.0001^{* *}$ \\
\hline & & Color*stage & $1.42_{2,71}$ & 0.248 \\
\hline & Copulation (D) & Color & $3.33_{1,71}$ & 0.072 \\
\hline & & Stage & $8.95_{2,71}$ & $0.0003^{* *}$ \\
\hline & & Color*stage & $0.51_{2,71}$ & 0.605 \\
\hline
\end{tabular}

(D), duration. Boldface indicates statistical significance and asterisk indicates significance after False Discovery Rate correction.

harass orange females with bites and chases more than white females (Figure 4A; $P=0.032$ and $P=0.033$ respectively, both non-significant after adjustment for FDR). By contrast, male aggressive behavior was influenced primarily by female reproductive stage with males performing significantly more lateral displays to gravid females than non-receptive or receptive females $\left[t_{(71)}=-2.84, P=0.006\right.$ and $t_{(71)}=2.58, P=0.012$ respectively; Figure 4B]. Males also copulated more frequently and for a longer duration with receptive females than non-receptive or gravid females $\left[t_{(71)}=-4.11, P=0.0001\right.$ and $t_{(71)}=-3.23$, $P=0.002$ respectively]. There was also a trend for males to copulate more often with orange females than white females irrespective of female reproductive stage $\left[t_{(71)}=2.03, P=0.046\right.$; not significant after adjustment for FDR].

\section{EXPERIMENT 2: FEMALE COLORATION AND MALE COURTSHIP INVESTMENT}

There were significant effects of female color on all male behaviors excluding latency to the initial behavioral response [Latency: $F_{(3,30)}=0.87, P=0.467$; headbobs: $F_{(3,30)}=4.48, P=0.01$; pushups: $F_{(3,30)}=3.34, P=0.032$; bites: $F_{(3,30)}=3.42, P=$

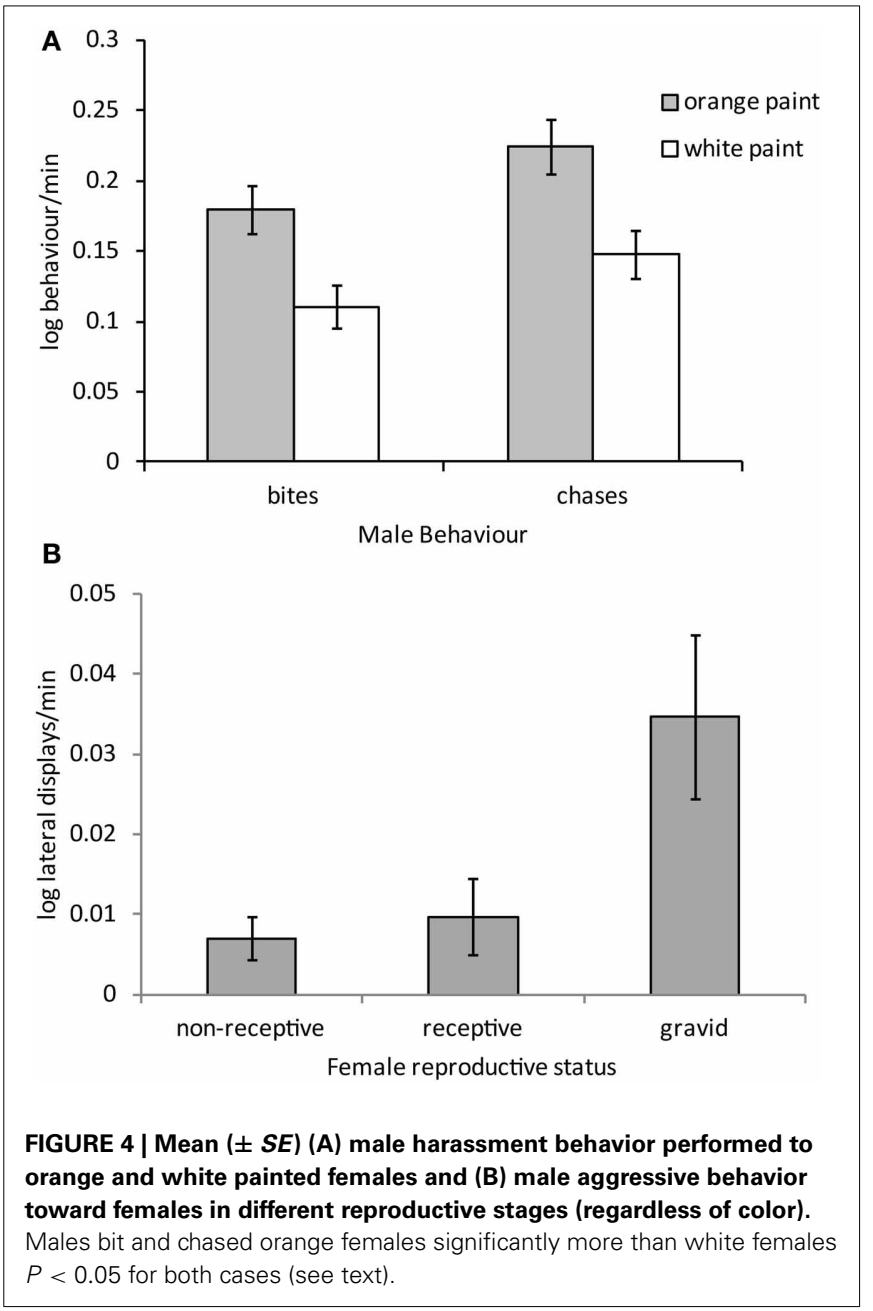

0.03 and chases: $\left.F_{(3,30)}=4.77, P=0.008\right]$. Males performed significantly more head bobs and push ups to small patch than orange or pale females [headbobs: $t_{(30)}=-2.28, P=0.03$; $t_{(30)}=-3.50, P=0.002$; pushups: $t_{(30)}=-2.13, P=0.041$; $t_{(30)}=-2.91, P=0.007$ respectively], and significantly more to no-UV-orange than pale females [headbobs: $t_{(30)}=2.33$, $P=0.027$; pushups: $t_{(30)}=2.09, P=0.045$; Figure 5A]. Males bit and chased no-UV-orange, orange and small orange patch females significantly more than pale orange females [bites: noUV-orange: $t_{(30)}=2.51, P=0.018$; orange: $t_{(30)}=2.25, P=$ 0.032 ; small patch: $t_{(30)}=-2.70, P=0.011$ and chases: no-UVorange: $t_{(30)}=2.53, P=0.017$; orange: $t_{(30)}=3.57, P=0.001$; small patch: $t_{(30)}=-2.55, P=0.016$; Figure 5B]. Overall, males courted females with small orange patches the most and harassed females with intense orange coloration the most, regardless of the presence of UV. They clearly invested least effort, in terms of both courtship and harassment behaviors, into females with pale orange coloration.

\section{DISCUSSION}

We tested whether female ornamentation signals reproductive condition and alters male courtship investment via experiments manipulating female coloration. Specifically, our experiments 


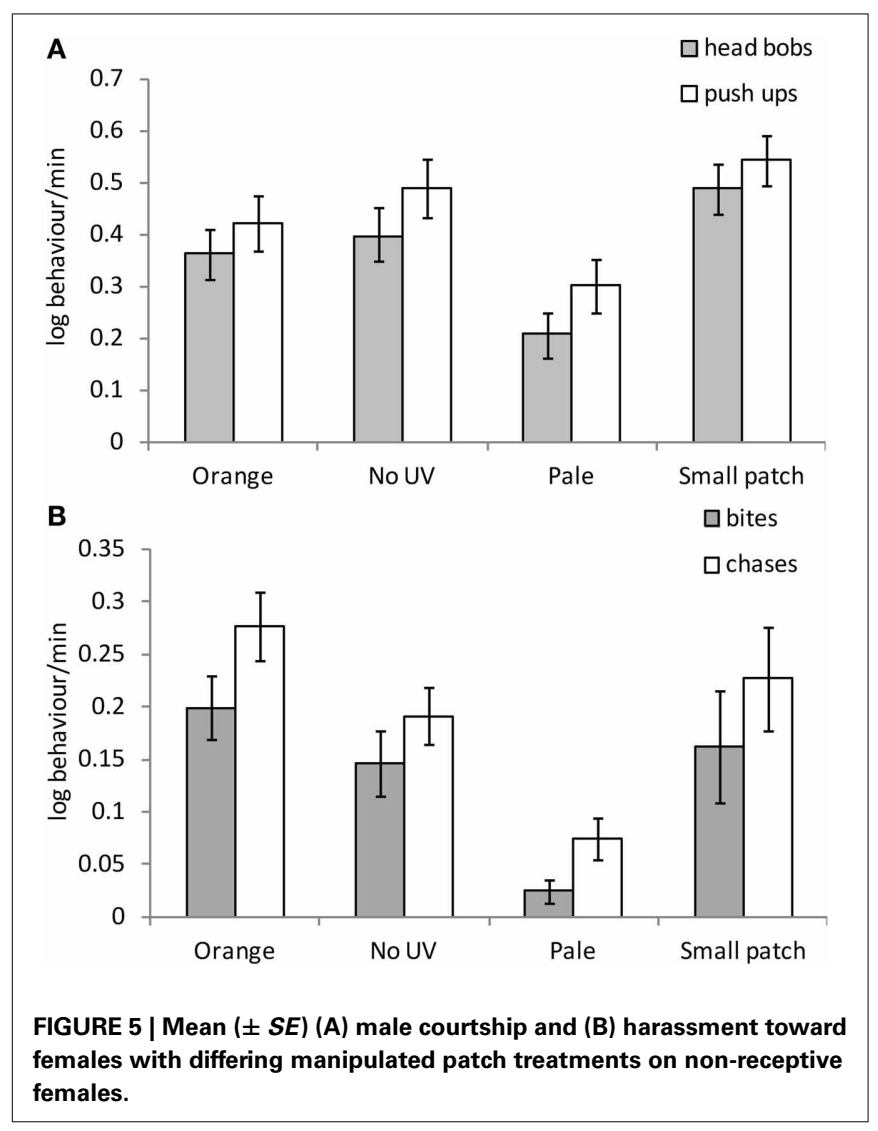

aimed to distinguish the role of color from behavior in signaling female reproductive condition to males and to test whether males altered their courtship investment based on the intensity, size, and presence of a UV component of female-specific orange color patches. Our color manipulations used paints that were matched to natural lizard colors using spectrophotometry. Although visual models showed that the paints appeared slightly more contrasting against salt crust than natural lizard coloration, males responded to females in the same manner as they did toward unmanipulated females (Chan et al., 2009). Furthermore, visual models indicate that the differences among orange paint treatments (orange, pale, no-UV-orange) can be perceived by lizards and closely approximated the natural variation seen in female coloration (except for no-UV-orange for which there is no natural analog).

\section{DISTINGUISHING THE ROLE OF COLOR FROM BEHAVIOR IN SIGNALING REPRODUCTIVE CONDITION}

As expected, female behavior was only influenced by reproductive stage, regardless of paint manipulation, confirming previous studies showing that paint manipulations do not alter the behavior of painted individuals in lizards (e.g., Cooper, 1984; Baird, 2004; Stuart-Fox and Johnston, 2005). Male behavior however, was weakly influenced both female color and strongly influenced by reproductive stage. There was a tendency for males to chase, bite, and copulate more with orange than white females, irrespective of reproductive state. These results are consistent with observations in nature (Mitchell, 1973; Olsson, 1995a) and correlative data showing that male harassment and courtship did not decline once physiological receptivity ceased (Chan et al., 2009). In contrast to the relatively weak effects of coloration, male behavior was strongly affected by female reproductive stage, regardless of coloration. Males copulated more frequently with receptive females than non-receptive or gravid females, consistent with females' behavioral acceptance of copulations during this stage. Males also performed more aggressive lateral threat displays to gravid females than all non-gravid females. This is because when gravid females performed lateral displays, males would often respond briefly with a lateral display; however, they would then continue to swiftly approach the female and attempt to force copulation in which case the female would flip onto her back.

Female lateral displays are similar to those of male threat displays, which are usually displayed in male-male rivalry and defense of territories. Given that these behaviors appear similar in both sexes, previous researchers have proposed the "aggression avoidance hypothesis," which suggests that conspicuous female coloration facilitates sex recognition, allowing females to perform courtship rejection displays (which closely resemble male aggressive displays) while avoiding aggressive responses to these displays from territorial males (Cooper and Greenberg, 1992). This hypothesis predicts that males should harass orange gravid (i.e., behaviorally rejecting) females less than white gravid females. That is, we would expect to see an interaction between color and reproductive stage. However, we found no evidence for this, suggesting that female-specific orange coloration does not function to either reduce male harassment or facilitate sex recognition.

\section{INFLUENCE OF FEMALE ORANGE COLORATION ON MALE COURTSHIP INVESTMENT}

Qualitative differences in female coloration including intensity and patch size influenced male investment into courtship and harassment. Male courtship investment and harassment was greatest toward females with small patches and more intense orange coloration respectively. Males courted and harassed pale orange females the least. These differences could be driven by differences in the absolute size and intensity of the orange patches, or the contrast between the orange, white and gray/black patches. In sticklebacks, for example, new evidence suggests that the contrast between the iridescent blue eye and the red throat is more important for female mate choice than the redness of the throat (Flamarique et al., 2013). In Lake Eyre dragons, small patches are bordered by white, which has high contrast against both the orange patches and black stripe. Contrast between the pale orange and gray stripe is markedly lower and the white strips bordering the orange throat patches are less defined in females with larger orange patches. Thus, the contrast between ventral color patches may be the primary cue used by males to assess females.

Regardless of the specific visual cue, there are two explanations for the observed differences in male behavior toward females differing in coloration. The first explanation is that small patches may signal that the female is more likely to be receptive, given that gravid females are larger due to developing eggs and the absolute size of orange patches is therefore also larger (Chan et al., 2009). Thus, orange color patches may function as "amplifier" signals, 
facilitating male assessment of female reproductive condition, as appears to be the case in ornate tree lizards Urosaurus ornatus (Zucker and Boecklen, 1990). Similarly, female orange coloration is most likely to be pale immediately prior to or after laying or prior to females becoming receptive. Females are usually unwilling to mate during these periods, perhaps explaining why males bite and chase such females less than those with intensely orange patches.

An alternative reason why males are more likely to court and harass females with smaller, more intensely orange patches is that the size, intensity and/or contrast of orange color patches signal aspects of female reproductive quality. Previously, Chan et al. (2009) found that female body condition and size were not correlated with the intensity of orange coloration; although there was a trend toward a correlation between the maximum relative area of orange throat coloration and the total number of eggs laid over a breeding season. These results are fairly inconclusive regarding the relationship between color expression and female quality because the sample sizes for female reproductive output were small. However, color intensity may be related to some other aspect of female reproductive quality, such as parasite load (Weiss, 2006). Experiments to identify female fitness correlates of orange coloration are required before we can be confident of the relationship between female color expression and reproductive quality.

\section{EVOLUTION OF FEMALE ORNAMENTATION}

Given that orange coloration increases male harassment the key question is why do females maintain orange coloration when no longer receptive? There are two possible explanations. Firstly, the sex steroids involved in the expression of orange coloration may also mediate the expression of aggressive courtship rejection behaviors (Jessop et al., 2009). Sex steroids such as testosterone and progesterone are involved in the development and maintenance of orange pigmentation and also play a role in mediating female rejection behaviors in lizards (Cooper and Ferguson, 1972a,b; Medica et al., 1973; Cooper and Crews, 1987; Cooper and Greenberg, 1992; Jessop et al., 2009). Previous experiments have shown that in both Lake Eyre dragons and keeled earless lizards Holbrookia propinqua, levels of progesterone and testosterone are strongly correlated with initial intensification of color and that high levels are maintained when females are gravid and exhibiting aggressive courtship rejection displays (Cooper and Crews, 1987; Jessop et al., 2009). It is therefore possible that in Lake Eyre dragons, once the pigments are deposited they cannot be rapidly eliminated while progesterone and testosterone levels remain high to enable females to behaviorally reject male courtship and copulation attempts (Jessop et al., 2009). Further evidence for this hypothesis is that only one species of lizard is reported to show characteristic breeding coloration when gravid and not perform rejection displays (Carpenter and Ferguson, 1977), and no species are reported to perform aggressive rejection displays in the absence of female-specific coloration altogether (reviewed in Cooper and Greenberg, 1992).

A second reason that females may maintain orange coloration while gravid, despite incurring costs of persistent male harassment, is that orange coloration reduces predation during rejection displays. Previous experiments have demonstrated that although models of flipped over females exposing ventral orange coloration were highly conspicuous to birds, they were attacked much less frequently than cryptically cultured (upright) models (McLean et al., 2010). This suggests that birds, the primary predators of this species, avoid orange females or do not recognize them as potential prey (McLean et al., 2010). Thus, in this species, the evolution of female ornamentation may reflect a complex interaction between sexual conflict over mating frequency, physiological constraints, and predation risk. More broadly, our study provides rare evidence that female coloration can influence male courtship investment in species with conventional sex roles and no paternal care.

\section{ACKNOWLEDGMENTS}

Funding was from the Australian Research Council (DP0772215) and the University of Melbourne (ECR 600065). South Australian Department of Environment and Heritage permit to undertake scientific research S25421_1; Wildlife Ethics Committee approval 13/2007; University of Melbourne Animal Ethics Committee approval 0701400.

\section{REFERENCES}

Amundsen, T. (2000a). "Female ornaments: genetically correlated or sexually selected?" in Animal Signals: Signalling and Signal Design in Animal Communication, eds Y. Espmark, T. Amundsen, and G. Rosenqvist (Trondheim: Tapir Academic Press).

Amundsen, T. (2000b). Why are female birds ornamented? Trends Ecol. Evol. 15, 149-155. doi: 10.1016/S0169-5347(99)01800-5

Amundsen, T., and Forsgren, E. (2001). Male mate choice selects for female coloration in a fish. Proc. Natl. Acad. Sci. U.S.A. 98, 13155-13160. doi: 10.1073/pnas.211439298

Andersson, S., and Amundsen, T. (1997). Ultraviolet colour vision and ornamentation in bluethroats. Proc. R. Soc. Lond. B 264, 1587-1591. doi: 10.1098/rspb.1997.0221

Baird, T. A. (2004). Reproductive coloration in female collared lizards, Crotophytus collaris, stimulates courtship by males. Herpetologica 60, 337-348. doi: 10.1655/03-17

Bajer, K., Molnár, O., Török, J., and Herczeg, G. (2010). Female European green lizards Lacerta viridis prefer males with high ultraviolet throat reflectance. Behav. Ecol. Sociobiol. 64, 2007-2014. doi: 10.1007/s00265-010-1012-2

Baldauf, S. A., Bakker, T. C. M., Kullmann, H., and Thunken, T. (2011). Female nuptial coloration and its adaptive significance in a mutual mate choice system. Behav. Ecol. 22, 478-485. doi: 10.1093/beheco/arq226

Barbour, H. R., Archer, M. A., Hart, N. S., Dunlop, S. A., Beazley, L. D., and Shand, J. (2002). Retinal characteristics of the ornate dragon lizard, Ctenophorus ornatus. J. Comp. Neurol. 450, 334-344. doi: 10.1002/cne.10308

Birkhead, T. R. (1995). Sperm competition: evolutionary causes and consequences. Reprod. Fertil. Dev. 7, 755-775. doi: 10.1071/RD9950755

Blumstein, D. T., and Daniel, J. C. (2007). Quantifying Behavior the J Watcher Way. Sunderland, MA: Sinauer Associates.

Carpenter, C. C., and Ferguson, G. W. (1977). "Variation and evolution of stereotyped behaviour in reptiles," in Part I. A Survey of Stereotyped Reptilian Behavioural Patterns, eds C. Gans and D. W. Tinkle (New York, NY: Academic Press), 355-554.

Chan, R., Stuart-Fox, D., and Jessop, T. S. (2009). Why are females ornamented? A test of the courtship stimulation and courtship rejection hypotheses. Behav. Ecol. 20, 1334-1342. doi: 10.1093/beheco/arp136

Cooper, W. E. (1984). Female secondary sexual coloration and sex recognition in the keeled earless lizard, Holbrookia propinqua. Anim. Behav. 32, 1142-1150. doi: 10.1016/S0003-3472(84)80230-4

Cooper, W. E., and Crews, D. (1987). Hormonal induction of secondary sexual coloration and rejection behavior in female keeled earless lizards, Holbrookia propinqua. Anim. Behav. 35, 1177-1187. doi: 10.1016/S0003-3472(87)80174-4 
Cooper, W. E., and Ferguson, G. W. (1972a). Relative effectiveness of progesterone and testosterone as inductors of orange spotting in female collared lizards. Herpetologica 28, 64-65.

Cooper, W. E., and Ferguson, G. W. (1972b). Steroids and color change during gravidity in the lizard, Crotaphytus collaris. Gen. Comp. Endocrinol. 18, 69-72. doi: 10.1016/0016-6480(72)90081-0

Cooper, W. E., and Greenberg, N. (1992). "Reptilian coloration and behavior," in Hormones, Brain, and Behavior, Biology of the Reptilia. Vol. 18, eds C. Gans and D. Crews (Chicago, IL: University of Chicago Press), 298-422.

Cunningham, E. J. A. (2003). Female mate preferences and subsequent resistance to copulation in the mallard. Behav. Ecol. 14, 326-333. doi: 10.1093/beheco/14.3.326

Eberhard, W. G. (2002). The function of female resistance behavior: intromission by male coercion vs. female cooperation in sepsid flies (Diptera: Sepsidae). Rev. Biol. Trop. 50, 485-505.

Flamarique, I. N., Bergstrom, C., Cheng, C. L., and Reimchen, T. E. (2013). Role of the iridescent eye in stickleback female mate choice. J. Exp. Biol. 216, 2806-2812. doi: 10.1242/jeb.084889

Gavrilets, S., Arnqvist, G., and Friberg, U. (2001). The evolution of female mate choice by sexual conflict. Proc. R. Soc. Lond. B 268, 531-539. doi: 10.1098/rspb.2000.1382

Gladbach, A., Gladbach, D. J., Kempenaers, B., and Quillfeldt, P. (2010). Femalespecific colouration, carotenoids and reproductive investment in a dichromatic species, the upland goose Chloephaga picta leucoptera. Behav. Ecol. Sociobiol. 64, 1779-1789. doi: 10.1007/s00265-010-0990-4

Gosden, T. P., and Svensson, E. I. (2009). Density-dependent male mating harassment, female resistance, and male mimicry. Am. Nat. 173, 709-721. doi: $10.1086 / 598491$

Jessop, T. J., Chan, R., and Stuart-Fox, D. (2009). Sex steroid correlates of femalespecific coloration, behaviour and reproductive state in Lake Eyre dragons, Ctenophorus maculosus. J. Comp. Physiol. A 195, 619-630. doi: 10.1007/s00359009-0437-4

Kemp, D. J. (2008). Female mating biases for bright ultraviolet iridescence in the butterfly Eurema hecabe (Pieridae). Behav. Ecol. 19, 1-8. doi: 10.1093/beheco/arm094

Kraaijeveld, K., Gregurke, J., Hall, C., Komdeur, J., and Mulder, R. A. (2004). Mutual ornamentation, sexual selection, and social dominance in the black swan. Behav. Ecol. 15, 380-389. doi: 10.1093/beheco/ $\operatorname{arh} 023$

LeBas, N. R., and Marshall, N. J. (2000). The role of colour in signalling and male choice in the agamid lizard Ctenophorus ornatus. Proc. R. Soc. Lond. B 267, 445-452. doi: 10.1098/rspb.2000.1020

Lim, M. L. M., Li, J. J., and Li, D. (2008). Effect of UV-reflecting markings on female mate-choice decisions in Cosmophasis umbratica, a jumping spider from Singapore. Behav. Ecol. 19, 61-66. doi: 10.1093/beheco/arm100

Loew, E. R., Fleishman, L. J., Foster, R. G., and Provencio, I. (2002). Visual pigments and oil droplets in diurnal lizards: a comparative study of Caribbean anoles. J. Exp. Biol. 205, 927-938.

McLean, C. A., Moussalli, A., and Stuart-Fox, D. (2010). The predation cost of female resistance. Behav. Ecol. 21, 861-867. doi: 10.1093/beheco/arq072

Medica, P. A., Turner, F. B., and Smith, D. D. (1973). Hormonal induction of color change in female leopard lizard, Crotaphytus wislizenii. Copeia 1973, 658-661. doi: $10.2307 / 1443064$

Mitchell, F. J. (1973). Studies on the ecology of the agamid lizard Amphibolorus maculosus. Trans. R. Soc. S. Aust. 97, 47-76.

Nordeide, J. T., Kekalainen, J., Janhunen, J., and Kortet, R. (2013). Female ornaments revisited - are they correlated with offspring quality? J. Anim. Ecol. 82, 26-38. doi: 10.1111/1365-2656.12021

Olsson, M. (1995a). Forced copulation and costly female resistance behavior in the Lake Eyre dragon, Ctenophorus maculosus. Herpetologica 51, $19-24$.

Olsson, M. (1995b). Territoriality in Lake Eyre dragons Ctenophorus maculosus - are males superterritorial? Ethology 101, 222-227. doi: 10.1111/j.1439 0310.1995.tb00360.x
Olsson, M., Stuart-Fox, D., and Ballen, C. (2013). Genetics and evolution of colour patterns in reptiles. Sem. Cell Dev. Biol. 24, 529-541. doi: 10.1016/j.semcdb. 2013.04.001

Rowland, W. J. (1982). Mate choice by male sticklebacks, gasterosteus-aculeatus. Anim. Behav. 30, 1093-1098. doi: 10.1016/S0003-3472(82)80199-1

Rubenstein, D. R. (2012). Sexual and social competition: broadening perspectives by defining female roles Introduction. Philos. Trans. R. Soc. B Biol. Sci. 367, 2248-2252. doi: 10.1098/rstb.2011.0278

Rubenstein, D. R., and Lovette, I. J. (2009). Reproductive skew and selection on female ornamentation in social species. Nature 462, 786-789. doi: 10.1038/nature08614

Shine, R., Langkilde, T., and Mason, R. T. (2003). Cryptic forcible insemination: male snakes exploit female physiology, anatomy, and behavior to obtain coercive matings. Am. Nat. 162, 653-667. doi: 10.1086/378749

Shine, R., and Mason, R. T. (2005). Does large body size in males evolve to facilitate forcible insemination? A study on garter snakes. Evolution 59, 2426-2432. doi: $10.1554 / 05-122.1$

Siddiqi, A., Cronin, T. W., Loew, E. R., Vorobyev, M., and Summers, K. (2004). Interspecific and intraspecific views of color signals in the strawberry poison frog Dendrobates pumilio. J. Exp. Biol. 207, 2471-2485. doi: 10.1242/jeb.01047

Stuart-Fox, D., Moussalli, A., Marshall, J., and Owens, I. P. F. (2003). Conspicuous males suffer higher predation risk: visual modelling and experimental evidence from lizards. Anim. Behav. 66, 541-550. doi: 10.1006/anbe.2003.2235

Stuart-Fox, D. M., and Johnston, G. R. (2005). Experience overrides colour in lizard contests. Behaviour 142, 329-350. doi: 10.1163/1568539053778265

Tobias, J. A., Montgomerie, R., and Lyon, B. E. (2012). The evolution of female ornaments and weaponry: social selection, sexual selection and ecological competition. Philos. Trans. R. Soc. B Biol. Sci. 367, 2274-2293. doi: $10.1098 /$ rstb. 2011.0280

Verhoeven, K. J. F., Simonsen, K. L., and McIntyre, L. M. (2005). Implementing false discovery rate control increasing your power. Oikos 108, 643-647. doi: 10.1111/j.0030-1299.2005.13727.x

Vorobyev, M., and Osorio, D. (1998). Receptor noise as a determinant of colour thresholds. Proc. R. Soc. Lond. B 265, 351-358. doi: 10.1098/rspb.1998.0302

Watson, N. L., and Simmons, L. W. (2010). Reproductive competition promotes the evolution of female weaponry. Proc. R. Soc. Lond. B 277, 2035-2040. doi: 10.1098/rspb.2009.2335

Weiss, S. L. (2006). Female-specific color is a signal of quality in the striped plateau lizard (Sceloporus virgatus). Behav. Ecol. 17, 726-732. doi: 10.1093/beheco/arl001

Xu, M. Z., and Fincke, O. M. (2011). Tests of the harassment-reduction function and frequency-dependent maintenance of a female-specific color polymorphism in a damselfly. Behav. Ecol. Sociobiol. 65, 1215-1227. doi: 10.1007/s00265010-1134-6

Zucker, N., and Boecklen, W. (1990). Variation in female throat coloration in the tree lizard (Urosaurus ornatus) - relation to reproductive-cycle and fecundity. Herpetologica 46, 387-394.

Conflict of Interest Statement: The authors declare that the research was conducted in the absence of any commercial or financial relationships that could be construed as a potential conflict of interest.

Received: 01 December 2013; accepted: 27 January 2014; published online: 27 February 2014

Citation: Stuart-Fox D and Goode JL (2014) Female ornamentation influences male courtship investment in a lizard. Front. Ecol. Evol. 2:2. doi: 10.3389/fevo.2014.00002 This article was submitted to Behavioral and Evolutionary Ecology, a section of the journal Frontiers in Ecology and Evolution.

Copyright (c) 2014 Stuart-Fox and Goode. This is an open-access article distributed under the terms of the Creative Commons Attribution License (CC BY). The use, distribution or reproduction in other forums is permitted, provided the original author (s) or licensor are credited and that the original publication in this journal is cited, in accordance with accepted academic practice. No use, distribution or reproduction is permitted which does not comply with these terms. 